\title{
Creating Meaningful Foreign Language Environment by Means of Content-based Starters
}

\author{
Maiia Karpushyna ${ }^{1}$, Ihor Bloshchynskyi ${ }^{1, *}$, Alona Nakonechna ${ }^{2}$, Kateryna Skyba ${ }^{2}$ \\ ${ }^{1}$ Faculty of Foreign Languages and Humanities, Bohdan Khmelnytskyi National Academy of the State Border Guard Service of \\ Ukraine, Ukraine \\ ${ }^{2}$ Faculty of International Relations, Khmelnytskyi National University, Ukraine
}

Received October 6, 2019; Revised November 14, 2019; Accepted November 21, 2019

Copyright $\bigcirc 2019$ by authors, all rights reserved. Authors agree that this article remains permanently open access under the terms of the Creative Commons Attribution License 4.0 International License

\begin{abstract}
The issues of creating foreign language environment in the English class by means of content-based warm-ups at its initial stage have been revealed in the research. Having analyzed the investigations on the issues under discussion, the role of the class starters and their contribution to the general second language teaching strategy and cadets' inducement to learn a foreign language in particular, have been defined. The expectation hypothesis suggests that content-based starters will exert a beneficial influence on cadets and help improve their academic results. Four cadets' groups of the Faculty of Foreign Languages and Humanities who acquire 035 Philology specialty were involved in the experiment in order to test the hypothesis. The methodology of the experiment includes qualitative and quantitative methods of data collection and analysis. Special focus has been made on the professional training of the future border guards whose responsibilities presuppose the ability to interview the foreigners at the international border crossing points as well as questioning irregular migrants beyond them. The result of the experiment demonstrated the validity of our expectation: the scores of the experimental groups were 5,64 higher in comparison with the control groups' results.
\end{abstract}

Keywords Meaningful, Content-based Starter, True-to-life, Subsequent Acquisition, Academic Results, Speaking Skills

\section{Introduction}

To get cadets absorbed in a foreign language environment is a crucial task of every instructor who is anxious to get them engaged in learning environment and make them excited about a topic. They are also conscious of adapting cadets to a new content of a lesson as well as to 'break ice' in communication and get them motivated for learning from the start. Special role in performing this task is given to the lesson starters. Starters can trigger any learning activity, set relevant pace, create psychological atmosphere, develop spontaneous speech, intensify cadets' attention, as well as prepare their organs of perception and speech for listening and speaking English. Although instructors acknowledge the contribution of each lesson stage, they cannot diminish the value of starters, as the latter often receive less attention than they should. Taking into consideration that border checks officers should be able to switch from their native language to a foreign one in order to accomplish effectively their tasks at the international airports, sea and highway border crossing points during passport control, as well as border surveillance officers are expected to question irregular migrants, instructors are concerned about all classroom potentials in teaching fluent foreign communication. Special role in cadets' training is given to starters.

\subsection{The Aim}

The objective of this research is to verify the hypothesis: content-based starters used on a regular basis make positive impact on the cadets' academic results in performing their speaking skills.

\subsection{Tasks}

1. To analyze the investigations on the problem of defining the impact of the starters on subsequent students' performance in the ESL class;

2. To find out the level of the cadets' academic performance of speaking activities at the beginning of the pedagogical experiment;

3. To determine the level of academic progress of the cadets' achievements of both efficiency and gains in 
speaking performance at the end of the pedagogical experiment.

\section{Materials and Methods}

\subsection{Literature Review}

The growth of globalization of travel and trade as well as the predominance of English in the media, particularly on the internet, has strongly influenced language education policy. The range of technologies for use in language learning and teaching has become very diverse and more available. Such scholar as I. Bloshchynskyi [1] emphasized the significance of informational and communication technologies usage during future Border Guard officers' independent foreign language professional training for state examinations. But academic achievements depend on the complex of different teaching techniques used for all sorts of specific language learning activities, such as oral practice as well as reading and writing skills development. Vital part of teaching English belongs to starters that are activities to warm up the students at the start of a class. The issue of using starters as a teaching and learning tool has been studied by many scholars. Hadfield [4] considers that warm-up is aimed at energizing people, getting them moving around and talking to each other at the beginning of a lesson and putting them in the spirits for learning. Ur and Wright [7] studied a quick warm-up for the class beginning as the way of getting students into the right mood for learning. They advise to link each short activity with what has gone before or what is coming after, in topic. Dornyei [2] finds a strong relation between motivation and warming up activities, which arouse the students' curiosity and attention, create an attractive image for the class. García and Martín [3] assert that warm-up is like a ship that takes the learners for a journey from known to unknown as an attempt to activate their potential and passive vocabulary. Warming up activities are designed according to some principles, - Velandia [8] states. They must go at the beginning, be short and related to the topic, be useful and content-related to continue the class, prepare them for a period of concentration, and be interesting and enjoyable. But the problem of creating meaningful foreign language environment in the English class by means of content-based starters at Bohdan Khmelnytskyi National Academy of the State Border Guard Service of Ukraine has not been entirely researched yet. Meanwhile, the needs analyses of the future border guards' professional activity show that cadets of 035 Philology specialty have to be prepared for ESL communication in a particular language field concerning border checks and border surveillance. Consequently, the instructors try and implement all efficient techniques to satisfy future border guard officers' professional needs.

\subsection{Theoretical Analysis of the Problem}

Any activity, and speaking in particular, requires some training. In order to perform ESL communication, cadets should be prepared in advance, as well as be assisted in acquiring shape in order to immerse themselves into a meaningful foreign language environment. Therefore, the instructor's task is to help cadets overcome a ESL communication barrier, establish psychological contact in the group, create an atmosphere of friendly and effective communication, open and free exchange of information between them, motivate cadets to speak a foreign language. Execution of this task is achieved through training in true-to-life situations, warming-up exercises, ice-breakers, energizers, starters. They are activities that give energy or enable to produce an effect; shake up or awaken, inspire or specify mode. The analysis allows affirming that starters' goal is to introduce the learners into such a language environment that would contribute to:

- establishing the atmosphere of real-life communication [6];

- $\quad$ stirring up all the learners and creating a dynamic atmosphere in the class [4];

- $\quad$ setting off a line of learning process [3];

- maintaining concentration on the topic [8];

- building a bridge between prior and new knowledge [7];

Taking into consideration these featuring goals we presuppose that exercising content-based starters on a regular basis will improve cadets' subsequent acquisition of the lexical and grammatical material as well as communicative skills and provide a smooth transition into the topic. They may become a scaffold for the consecutive class activities and create the meaningful foreign language environment to excel in ESL learning.

\subsection{Participants}

The experiment was conducted in Bohdan Khmelnytskyi National Academy of the State Border Guard Service of Ukraine in 2018-2019. 39 cadets of the Faculty of Foreign Languages and Humanities, who acquire 035 Philology specialty (28 males and 11 females) took part in the experiment. The experimental (EG, $\mathrm{n}=20,15$ males and 5 females) and control (CG, $\mathrm{n}=19,13$ males and 6 females) groups were regimented. Both groups were composed of cadets of the same knowledge level, age and gender.

\subsection{Research Methodology}

The research methodology is associated with clarification of assumption that using content-based starters leads to better cadets' academic achievements. As we choose to achieve research objective via testing hypothesis, this research will follow deductive approach. It uses the qualitative methods of data collection and analysis 
in our study (interviews, focus groups, observation, case studies, problem situations etc.) and quantitative methods of data collection and analysis, on the other hand, including mean, mode and median. These methods are aimed at providing a foundation for content-based starters' potential in improving academic results of the Foreign Languages and Humanities Faculty cadets, whose specialty is 035 Philology.

\subsection{Research Procedure}

Having analyzed different resource books $[4,6,7]$, we have found out that warm-ups are differentiated according to their certain characteristics. The most efficient approaches towards creating a meaningful class environment are task-based, problem-based and content-based ones. In our opinion the latter is expected to link the initial stage of the class with its consecutive stages as well as to relate prior knowledge to the new content. All the activities that are used as starters encompass multiform communicative exercises, which depend on the English class topic, objectives and cadets' level of knowledge. Some of the use-proven starters taken from our "bank", adapted to the cadets' curriculum, are given below.

The easiest way to engage cadets into a meaningful foreign language environment from the point of view of developing the task is to exploit a problem-based question, famous people's quotation, contradictory judgments or discrepant opinions, which should be refuted. In such tasks, cadets use language for a purpose; and the first thing they focus their attention on is conveying a message. Such starters serve a splendid opportunity to develop cadets' ability to communicate freely and spontaneously in English.

Question time activity presupposes some preparatory work. As it is performed with the use of cards, each of which contains a question, the instructor is expected to prepare them in advance. The quantity of cards should correspond to the number of cadets, who get together to brainstorm the questions. The questions are aimed at running over the previous topic, or predicting the new one.

Basically, meaningful foreign language environment can be created by using a selection of interesting facts on the topic. Every cadet receives one sentence on a strip of paper, learns it by heart and in 2 minutes they ought to be mingling with the other cadets in order to share their fact with every member of the group. As a result, the cadets learn about the rest of the facts and memorize them. After finishing the mingling activity the learners try and call to memory as many facts as possible. The winner is the one who remembers the majority of the facts. If time does not permit the above, the task can be performed by cadets who stand in a circle and deliver messages to the group, so-called "Microphone" technique. This contributes to promoting interest in the topic.

Authentic video extracts, relevant to the subject, become an effective means of creating meaningful activities. They make learning more appealing and amusing; represent a valuable source of authentic language, as well as diverse genuine cultural contexts that enable learners to comprehend the real-life situations they are usually not exposed to; extend the range of teaching techniques and resources by offering the opportunity for role-playing, class debates etc. [5]. For instance, the extract from the film "Terminal" in 2-3 minutes introduces cadets to the real foreign language environment and provokes discussion about border checks of a stateless person in New York Terminal.

Essentially, the universal starter of any lesson is watching news from authentic web-sites. They can be an addition to any topic, satisfy cadets' different level of knowledge and help recognize and study the modern socio-political as well as professionally oriented vocabulary related to the problems of illegal migration, drug trafficking, human trafficking etc. Such video or audio news has a huge potential for making tasks, including:

- answer problem questions;

- find out the meaning of the numbers mentioned in the news;

- bring out the main message of the news;

- identify the problem and give your solution;

- predict the content of the news, making judgments based on particular items of vocabulary, etc.

A word cloud is an image composed of words used in a particular way: the size of each word indicates its frequency and importance for constructing a concept statement. It is often a challenging task for cadets who are expected to use all or at least some of the words in order to define the central concept. The activity can be very competing in case cadets are encouraged to use as many cloud words as possible. The task can be also performed as a team game. The so-called word clouds (word collages) are used to teach cadets to compose definitions, to generalize concepts, such as "clandestine entrant" (Figure 1). 


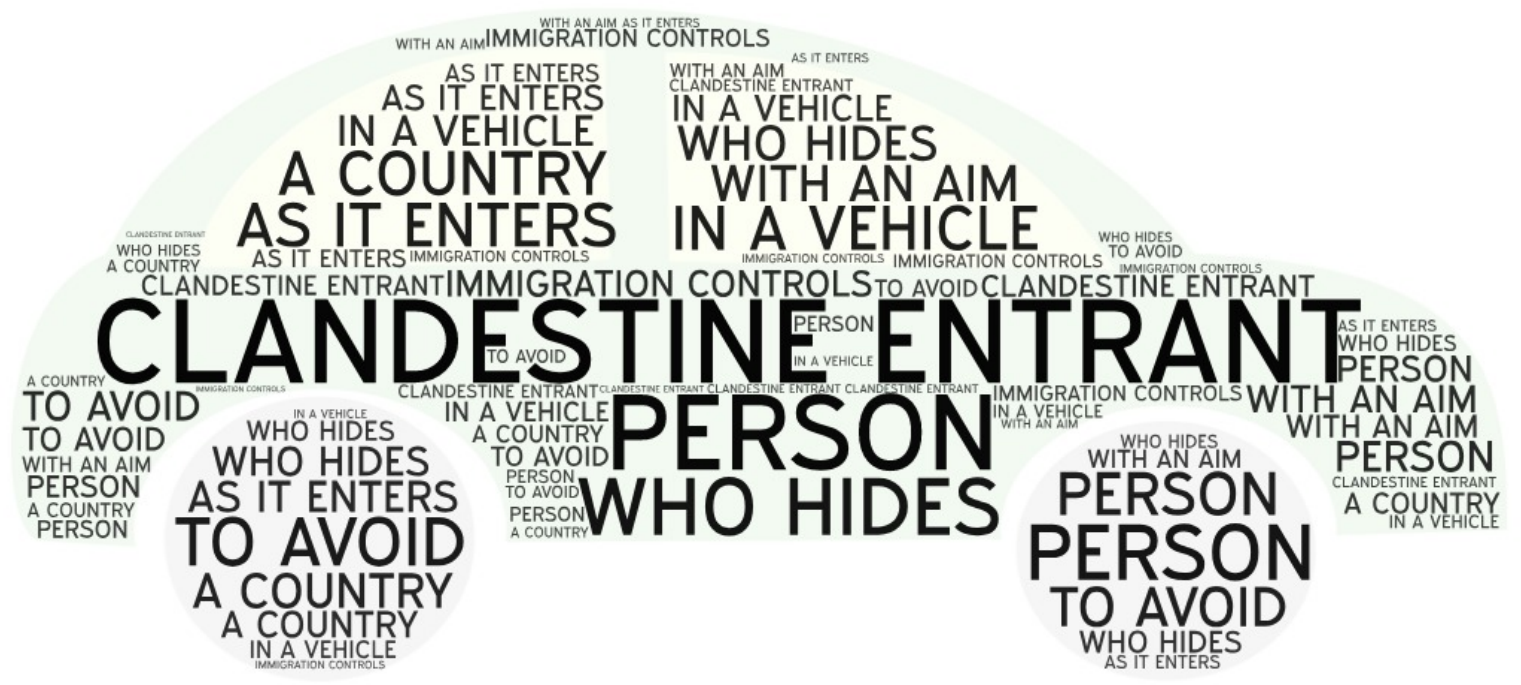

Figure 1. Word Cloud "What Clandestine Entrant Is"

Graphic organizers are great media, which help cadets shape thoughts or understand a problem. Using their creativity, cadets brainstorm their ideas to describe the details of the problem or find solutions to it. In order to find out and discuss the roots of juvenile delinquency, cadets work in groups and create mini-cases filling out decision trees, smart cards, spider diagrams etc. A true-to-life situation can be analyzed by the cadets with the use of problem analysis map. One of the professionally oriented and problem-based situations analyzed by the learners resulted in the below presented mind map (Figure 2).

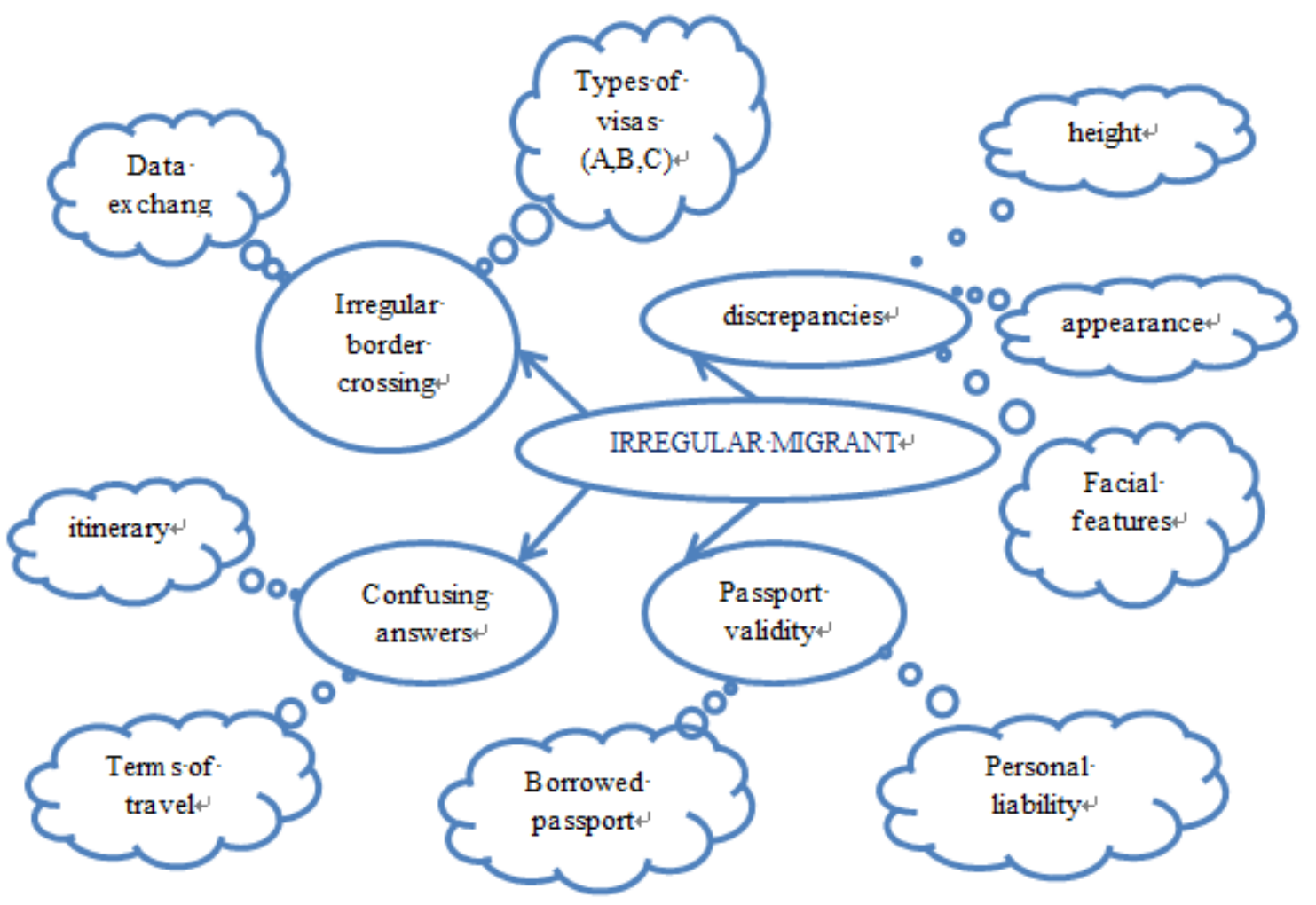

Figure 2. Problem Analysis Mind Map "Cross Border Procedure Detailed Analysis" 
A thrilling way to create meaningful foreign language environment is a vocabulary game. The instructor offers a list of words, for example, names denoting border crimes, from which cadets choose six and write them in a table. The instructor reads the definition of words randomly. When the cadets find the appropriate term in their table, they cross it out. The winner is the one who first crosses out all the terms in his/her table. For example, the list of terms may contain the following names of crimes: smuggling, bribery, human trafficking, drug trafficking etc.

The relevant definitions should be prepared in advance, and may include:

- $\quad$ illegal bringing goods into or out of the country;

- offering a sum of money or something valuable to an official in order to persuade him or her to do something;

- $\quad$ trade in people;

- the crime of selling, transporting, or illegally importing unlawful controlled substances such as heroin, cocaine, marijuana etc.

The same vocabulary can be used for a different task: compiling a word entry. Cadets are invited to give a definition of a selected term from the suggested list without telling anyone the term. Then, they read their definitions for the word entry without naming it, and the group defines the word. This task may also be prepared beforehand as a home assignment, in order to save time in the class and provide quick revision of the target vocabulary.

A special place among starters is occupied by personally-oriented tasks. They stimulate the use of cadets' own experience in communicative activities; fill their discourse with meaningful contents. For example, the experience of being acquainted with the peers from the first days of study at the academy may become an urgent topic for discussion. For this purpose, the instructor may offer to complete the "unfinished sentences":

- What I like about you is...

- It appears to me that an important difference between us is...

- What you / I need is...

- One thing that surprised me about you was...

In addition to unfinished sentences, personally-oriented questions facilitate effective learning and provide strong motivation for cadets to learn English because they can do that in more interesting ways than traditional class activities.

The last but not the least activity suggests dynamic involvement in personally meaningful communication. Cadets form two parallel lines, facing each other, with an equal number of cadets in each line. Everyone is talking to the person standing in front till the time they are given the order to switch to the next speaker in this face to face interaction. One of the two lines is designated as the "moving" line while the other remains "fixed". By every move cadets exchange their places: one - from the moving line to the fixed one and consequently the other - from the fixed to the moving one. After all partner changes, the cadets take their seats and use the information they discussed in a writing activity.

\section{Results}

To verify the hypothesis, the experiment has been carried out in four cadets' groups of the same knowledge level, age, gender and quantity composition. Each group contained nine or ten 20-year-old persons who were tested after having studied five units. The cadets were given a test and were interviewed to evaluate their speaking skills at the beginning of the experiment. To assess the cadets' progress, they were tested at the end of each semester. Apart from the above-mentioned procedures a mid-term control was undertaken to identify what should be changed, altered, maintained, improved, or expanded. An assessment task included a test and communicative situation, which, in our opinion, allowed the cadets to demonstrate their academic results. A test contained 25 multiple choice tasks, which covered the lexical and grammatical material learned in several units. Communicative situations were selected by blind choice and the learners were invited to bring out ideas concerning the problems raised in a situation. The cadets' abilities to spot a problem, describe its details, give their judgments and solution, deliver fluent speech and demonstrate confidence have been tested. All classes in groups A1 and A2 were introduced to starters on a regular basis; moreover, they were closely related to a certain unit's content. Groups B1 and B2 were also offered starters but not on a regular basis and they were not always necessarily content-based.

Before each unit the instructor did the constructive thinking on each class objectives and the content-based starters to satisfy them. Before every new topic, the bank of content-based starters has been prepared. Each topic included from ten to twelve classes. As a result, cadets did two tests each semester excluding the placement one. Instructors were offered an assessment chart to record each cadet's academic results (Table 1). The maximum grade cadets could get for each test paper is 25 and a content-based situation is also assessed at 25 points. 
Table 1. Instructor's Assessment Chart

\begin{tabular}{|l|c|}
\hline \multicolumn{1}{|c|}{ Cadet's name, surname } & Academic results \\
\hline Tasks & \\
\hline 1.Test (25 tasks), scored from 0 to 25 - one for each correct answer & \\
\hline 2.Communicative situation with maximum score 25 - five for each skill: & \\
\hline to spot a problem or problems & \\
\hline to describe their details & \\
\hline to give their judgments & \\
\hline to sort out simple, effective solutions to practical problems & \\
\hline to demonstrate fluent speech and confidence & \\
\hline Total score (50) & \\
\hline
\end{tabular}

Table 2. Dynamic analysis of the academic results

\begin{tabular}{|c|c|c|c|c|c|c|c|c|}
\hline \multirow{2}{*}{ Scores } & \multicolumn{4}{|c|}{$\begin{array}{c}\text { Control groups (B1, B2) } \\
(\mathrm{n}=19)\end{array}$} & \multicolumn{4}{c|}{$\begin{array}{c}\text { Experimental groups (A1, A2) } \\
(\mathrm{n}=20)\end{array}$} \\
\cline { 2 - 12 } & \multicolumn{2}{|c|}{ Initial results } & \multicolumn{2}{c|}{ Final results } & \multicolumn{2}{c|}{ Initial results } & \multicolumn{2}{c|}{ Final results } \\
\cline { 2 - 11 } & cadets & $\%$ & cadets & $\%$ & cadets & $\%$ & cadets & $\%$ \\
\hline high (46-50) & 2 & 10,53 & 3 & 15,79 & 2 & 10,00 & 9 & 45.00 \\
\hline sufficient (41-45) & 6 & 31,59 & 8 & 42,11 & 6 & 30,00 & 11 & 55,00 \\
\hline satisfactory (35-40) & 10 & 52,62 & 8 & 42,11 & 11 & 55,00 & 0 & 0 \\
\hline low (27-34) & 1 & 5,26 & 0 & 0 & 1 & 5,00 & 0 & 0 \\
\hline Average rate & \multicolumn{3}{|c|}{39,53} & \multicolumn{2}{|c|}{41,58} & \multicolumn{2}{|c|}{39,06} & \multicolumn{2}{|c|}{46,75} \\
\hline
\end{tabular}

Current final results analysis reveals that cadets, who were steadily exposed to content-based starters, were better prepared for the academic contexts they entered, so consequently they were able to perform more efficiently, effectively, appropriately and confidently.

The average score in the control groups is 2,05 higher at the end of the experiment in comparison with its beginning. The experimental groups' result is 7,69 higher. The divergence between the scores of the compared groups is 5,64 , which proves the validity of the hypothesis (Table 2).

\section{Discussion}

Before starting the research, we have carried out present situation analysis, target situation analysis and content analysis. Present situation analysis helped us find out cadets' current skills and rearrange groups according to the academic results they had demonstrated. Target situation analysis was done to specify the skills cadets need to perform their future duties, which presuppose interviewing the foreigners at the international border crossing points and questioning the irregular migrants beyond them. Therefore, cadets' training is aimed at learning target vocabulary to cover their needs. Content analysis was performed to evaluate the resources including meaningful starters.

According to the results of our research, the cadets were split into four groups with respect to their scores, that is high, sufficient, satisfactory, and low.
Cadets with the high level language performance demonstrated confidence in ESL fluent speech, easily spotted problems, described all details, gave grounds to their opinions and found out appropriate solutions to the problems. Their scores went between 46-50. This level was characterized by a great degree of cadets' autonomy.

Cadets, who fell into the group with sufficient knowledge and skills, showed few mistakes in a test. They could spot problems, but were not always able to describe all details, which caused sometimes uncertainty in delivering the interview, but they coped with making final decision. The scores in this group shifted between 41-45.

Satisfactory level cadets were characterized by low degree of confidence and ability to lead the conversation. Their test results were quite decent with 4-5 mistakes, but they often had difficulty in spotting all problems and could describe few details. Their weak point was inability of giving judgments, explanation. So, the scores were as diverse as $35-40$.

Cadets with low scores were characterized by poor results in each of five skills and more than 7 mistakes in a test. They used a limited number of lexical units, operated primitive grammar, therefore they failed to make a comprehensive decision in the majority of cases. Their scores vacillated between 27-34.

The results of the experiment allow us to conclude that the indicators of the experimental groups cadets showed significantly better final scores $(5,17$ higher) than of the control groups cadets'.

Thereafter, from creating a meaningful foreign language 
environment perspective, the use of starters can be viewed as a genuine scaffold for cadets' better target-language performance. Moreover, each cadet's language performance was evaluated with the help of specially designed assessment chart. The testing included lexical and grammatical knowledge as well as communication skills.

It confirmed our assumption that content-based starters used on a regular basis make positive impact on creating meaningful foreign language environment, which in its turn improves the cadets' speaking skills performance and as a result enhances their career prospects.

\section{Conclusions}

Bearing in mind the classroom experiment of using starters as a teaching tool for creating a meaningful foreign language environment as well as for enhancing cadets' academic results, it can be concluded that content-based starters definitely have a great potential to provide cadets with the situations of success at the later stages of the English class.

The profound analysis allows us to state that the content-based starters should be an integral part of each English class for the reasons that they help create topic-related and meaningful activities, activate both vocabulary and grammar, provide a link between the known and unknown, motivate cadets to learn as well as make them determined to succeed. In addition, they give cadets opportunity for spontaneous language production and prepare them for real life communication. Furthermore, content-based starters prove to be beneficial as they draw attention to the target language.

The results of the experiment emphasize the importance of systematic use of content-based starters since they tend to have a positive influence on the academic results demonstrated by the cadets of the experimental groups. The score growth in the experimental groups is 7,69 while in the control groups it is 2,05 . The final score in the experimental groups is 5,64 higher than in the control groups. Thus, the hypothesis that the usage of content-based starters on a regular basis would improve cadets' subsequent acquisition of the lexical and grammatical materials as well as communicative skills within a certain unit (or topic) has been validated.

The shared sample starters used to create meaningful foreign language environment have been tested by the instructors' own experience. The actual application of content-based starters has proved that the inventiveness of the instructors and the curiosity of the cadets can set the tone and what is more, establish a space for creative and critical thinking.

Future research will concern creating and implementing the problem-based tasks that bring into the open real situations of the future border guard officers' professional activities in the ESL class.

\section{REFERENCES}

[1] Bloshchynskyi, I. H. (2017). Usage of Anki specialised program application during future Border Guard officers' independent foreign language professional training for passing state examination. Information technologies and learning tools. 58 (2), 49-58. Retrieved from: https://journ al.iitta.gov.ua/index.php/itlt/article/view/1605.

[2] Dornyei, Z. (2001). Motivational strategies in the English classroom. Cambridge: Cambridge University Press.

[3] García, A. M., \& Martín, J. C. (2004). Something Old and Something New. Techniques to Improve the Lexical Inventory of EST Students: A Proposal. Revista Estudios Ingleses, 17, 43 6-44. Retrieved from: http://publicaciones. ua.es/filespubli/pdf/02144808RD25769742.pdf

[4] Hadfield, J. (2000). Classroom dynamics. Resource Book for Teachers. Oxford: Oxford University Press.

[5] Kaličanin, M. (2018). Controversy in the Classroom: The Case of Trainspotting / Milena Kaličanin // The Journal of Teaching English for Specific and Academic Purposes, Vol. 6 (1), 43-51.

[6] Ur P. (2009). A Course in Language Teaching: Practice of Theory. Cambridge: Cambridge University Press.

[7] Ur P., \& Wright A. (2002). Five Minute Activities. A Resource Book of Short Activities. Cambridge Handbooks for Language Teachers. Cambridge: Cambridge University Press.

[8] Velandia, R. (2008). The Role of Warming Up Activities in Adolescent Students' Involvement during the English Class. 